ISSN: $2594-4827$

\title{
MESTRADO E DOUTORADO EM REDE: A EXPERIÊNCIA NA ÁREA DE ENSINO COM AS REDES REAMEC E PROF-EPT
}

\author{
Tania Cremonini de Araújo-Jorge ${ }^{1}$ \\ Anunciata Cristina Marins Braz Sawada ${ }^{2}$
}

\section{RESUMO}

Refletimos aqui sobre a avaliação da Rede Amazônica de Ensino de Ciências (REAMEC) para antever lições aos próximos desafios para a Área de Ensino. Após uma introdução histórica sobre o surgimento da Pós-Graduação (PG) no Brasil, focamos nas experiências de constituição das 13 redes de PGque foram avaliadas em 2017. Destas, 9 utilizaram a nova ficha de avaliação de redes, concebida e aprovada pela CAPES para enfatizar os resultados das redes relativos a seus egressos e a sua inserção social $(60 \%$ do peso da avaliação). O uso desta ficha foi feito justamente na REAMEC e trouxe resultados positivos, que foram sistematizados no artigo, para que considerações pudessem ser tecidas relativamente a sua aplicação em novas redes, como o Prof-EPT e outras que estão sendo geradas na Área.

Palavras-chave: Pós-Graduação em Rede; Avaliação; Amazônia; Doutorado; Ensino.

\section{NETWORK FOR MASTER AND PHD: THE EXPERIENCE OF THE LEARNING AREA WITH THE NETS A REAMEC AND PROF-EPT}

\begin{abstract}
We reflect here on the evaluation of the Amazonian Network of Science Education (REAMEC) to anticipate lessons to the next challenges for the Learning Area. After a historical introduction about the emergence of PG in Brazil, we focused on the experiences of the creation of the 13 PG networks which were evaluated in 2017. Of these, 9 used the new network evaluation card, conceived and approved by CAPES to emphasize the results of the networks related to their graduates and their social insertion (60\% of the weight of the evaluation). The use of this form was done precisely at REAMEC and brought positive results, which were systematized in this paper, so that considerations could be woven in relation to its application in new networks, such as Prof-EPT and others that are being generated in the Area.
\end{abstract}

Key-words: Post-Graduation Network; Evaluation; Amazonia; Doctorate; Learning.

\footnotetext{
${ }^{1}$ Laboratório de Inovações em Terapias, Ensino e Bioprodutos, Instituto Oswaldo Crus, Fundação Oswaldo Cruz; Coordenadora da Área de Ensino da CAPES de 2013 a 2018; tania.araujojorge@gmail.com
}

${ }^{2}$ Laboratório de Inovações em Terapias, Ensino e Bioprodutos, Instituto Oswaldo Crus, Fundação Oswaldo Cruz; Doutoranda da Pós-Graduação em Ensino em Biociências e Saúde; acssawada@gmail.com 


\section{INTRODUÇÃO}

A Área de Ensino da CAPES foi criada em junho de 2011, a partir da Área de Ensino de Ciências e Matemática. Na primeira avaliação dos programas na nova Área, em 2013, destacava-se a recente presença da REAMEC (Rede Amazônica de Ensino de Ciências), com oDoutorado Acadêmicoem Rede de Educação em Ciências e Matemática (PPGECM), recém instituído, com objetivo de formar 100 doutores em Ensino de Ciência e Matemática na Amazônia. Naquele momento, a jovem rede, com sede em Cuiabá na Universidade Federal de Mato Grosso (UFMT) e mais dois polos físicos - em Manaus, na Universidade Estadual do Amazonas (UEA) e em Belém, na Universidade Federal do Pará (UFPA)- foi apenas acompanhada quanto ao seu processo de implantação. Em 2017, essa experiência pode ser plenamente avaliada, com um quadriênio completo e 72 doutores já formados de 2013 a 2017. O PPGECM avançou da nota 4 para a nota 5 , tendo o melhor desempenho acadêmico quantitativo de toda a Área, segundo os parâmetros analisados e registrados no relatório da avaliação quadrienal (ARAÚJO-JORGE; BORBA; SOVIERZOSKI, 2017). Neste mesmo ano, 2017, a Área de Ensino aprovava seu primeiro Mestrado Profissional em Rede em Educação Profissional e Tecnológica - Prof-EPT (FREITAS e cols., 2017). Nosso objetivo nesse artigo é refletir sobre a avaliação da REAMEC para antever lições para o Prof-EPT e os próximos desafios em rede para a Área de Ensino.

\section{A PÓS-GRADUAÇÃO EM REDE NO BRASIL}

As primeiras experiências de pós-graduação no Brasil remontam ao "Curso de Aplicação" do Instituto Oswaldo Cruz que oferecia em seus laboratórios cursos comformação para a pesquisa para graduados (sobretudo em Medicina), tendo formado 395 egressos até a década de 70 (ARAÚJO-JORGE, BARBOSA, OLIVEIRA, 2012, p.22). Na década de 30 Francisco Campos propôs uma Pós-Graduação no Brasil aos moldes europeus e na década de 40 o termo "pós-graduação" foi usado pela primeira vez no Estatuto da Universidade do Brasil (SANTOS, 2003, p. 628). Em 1951 foi criada a Coordenação de Aperfeiçoamento de Pessoal de Nível Superior - CAPES e desde então, nas décadas seguintes, o Sistema Nacional de Pós-Graduação (SNPG) veio 
crescendo com a organização de cursos de mestrado e de doutorado isolados, regulamentados pelo parecer 977, de 1965 (parecer Sucupira). Em seu livro sobre a PósGraduação, Darcy Ribeiro escreveu: “A experiência brasileira de pós-graduação nos últimos anos é a coisa mais positiva da história da educação superior no Brasil e é também a que tem que ser levada a sériopois é elemento essencial para o progresso e o desenvolvimento da Nação" (RIBEIRO, 1980).

A concepção de articulação interinstitucional em redes para oferta de cursos de pós-graduação, mais especificamente para Doutorado, começou a ser gestada no final da década de 90 e foi inaugurada pela parceria CNPq-CAPES em 2004, com a criação da RENORBIO (MEDEIROS; RONDON, 2018). Do sucesso dessa primeira experiência surgiu a formulação oficial do IV Plano Nacional de Pós-Graduação (PNPG), 20052010 (Brasil, 2004), que recomendava "Atuação em rede, para diminuir os desequilíbrios regionais na oferta e desempenho da pós-graduação e atender às novas áreas de conhecimento."

Explicitamente o PNPG 2005-2010 sugeria a

criação de novas tipologias regionais, diversas das existentes, com dados desagregados, permitindo diagnósticos e análise mais detalhados. O resultado desse procedimento permitirá uma melhor política indutora, permitindo a criação de redes e de parceria na pesquisa e na pós-graduação. (BRASIL, 2004, p. 56).

Também recomendava formas de operacionalização das redes de cooperação:

Na perspectiva de formação de redes, é fundamental a expansão de um programa de bolsas para estágio no Brasil, de fluxo contínuo, abertas a outros programas além do PROCAD e PQI, dentre outros. Este tipo de programa promoveria a interação entre grupos e laboratórios, permitindo o compartilhamento de infraestrutura entre grupos de pesquisa no país e estimularia a mobilidade dos pesquisadores. (BRASIL, 2004, p. 60).

Essa ideia foi plenamente adotada no V PNPG, 2011-2020 (BRASIL, 2010). Diversas outras redes foram compostas, nacionais e regionais, em nível de Doutorado Acadêmico, com foco na nucleação e fortalecimento de pesquisas, e em nível de Mestrado Profissional. O documento se definia como um "instrumento de políticas públicas e sua finalidade é a dinamização e o adensamento do SNPG”, propondo 
naquele momento cinco eixos estruturantes para o V PNPG, ainda vigente: 1- a expansão do SNPG; 2- criação de uma agenda nacional de pesquisa; 3. o aperfeiçoamento da avaliação; 4. a multi/interdisciplinaridade; 5. o apoio a outros níveis de ensino.

$\mathrm{O}$ estabelecimento de Redes de Pesquisae Pós-Graduação foi proposto pelo V PNPG como "um instrumento diferenciado das políticas públicas em exercício para atenuar o desequilíbrio regional" (...) buscando superar problemas comuns ao Cerrado, Amazônia e Nordeste: "massa crítica limitada, preocupações com a sustentabilidade ambiental ou com o desenvolvimento e a pobreza” (BRASIL 2010, p.220).

As redes de PPG têm como primeira vantagem, promover a convergência da massa crítica atuante em $C \& T$, particularmente em regiões em que ela é limitada. Esta convergência, que resulta em forte relação multi-institucional, diminui a redundância nos investimentos de infraestrutura e contribui para maior produtividade dos grupos financiados em seus projetos. Finalmente, as redes regionais de PPG poderão atenuar o ímpeto crescente de cursos de pós-graduação com equipes e currículos limitados que, via de regra, têm enorme dificuldade de galgar posição de destaque no ranking da CAPES (...). Pesquisa científica tem que produzir desenvolvimento. As Redes de PPG devem estabelecer suas agendas com essa ótica. (BRASIL, 2010, p.220).

A Avaliação da PG em 2017 teceu um quadro atual dessa construção de PósGraduações em rede, como mostrado na Tabela 1. Com pelo menos um relatório completo preenchido, no caso de mestrado e dois no caso de doutorado, foram acompanhados e avaliados 14 programas, sendo 06 acadêmicos (Doutorado) e 08 profissionais (Mestrado). Outros Programas em Rede, iniciados entre 2016 e 2018 já estão no SNPG, mas só passaram pela avaliação inicial (avaliação de curso novo APCN), e não pela avaliação completa junto com os demais programas. Esse foi o caso do Prof-EPT. Dos 14 Programas em rede avaliados, seis são diretamente ligados à formação continuada de professores para a Educação Básica e para as Licenciaturas: o Doutorado em Educação em Ciências e Matemática na Amazônia - REAMEC- e os Mestrados Profissionais em Rede Nacional em Matemática, Física, Letras, História e Artes, destacados em fundo cinza na Tabela 1. Os outros oito são relativos a temáticas relevantes para as respectivas Áreas de avaliação, seja a nível das regiões em que as redes foram implantadas, como os três Doutorados em Rede na Área de Biotecnologia, 
o Doutorado em Desenvolvimento e Meio Ambiente na Área de Ciências Ambientais e o Doutorado Multi-institucional em Química em Minas Gerais. Os demais também são Mestrados Profissionais, com foco no aumento da escala de formaçãode outros profissionais, sobretudo em gestão.

A Tabela 1 mostra que dos 13 programas em rede avaliados, nove utilizaram a nova "Ficha de Avaliação de Rede" concebida, discutida e aprovada pelo Conselho Técnico Científico do Ensino Superior da CAPES (CTC-ES) para a Avaliação Quadrienal de 2017. O CTC-ES já havia detectado que a ficha tradicional de avaliação de Programasindividuais não captava dados considerados relevantes para a avaliação das Redes. Mas deixou a critério de cada Área a adoção ou não da nova ficha já em 2017. Por isso ela foi incorporada aos Documentos das 11 Áreas que consideraram adequado avançar na introdução desse novo documento de avaliação da PG: a ficha de rede. Foi o caso da Área de Ensino, que resolveu adotar a ficha de rede inclusive para a avaliação da REAMEC. A maior parte dos programas acadêmicos em rede ainda preferiu manter as fichas tradicionais, ao contrário dos Programas Profissionais, que estrearam a ficha de Rede.Dos seis Doutorados em Rede, quatro utilizaram a ficha tradicional e dois utilizaram a nova ficha de Rede.

No que diferem as duas fichas? As fichas Tradicionais, tanto para programas Acadêmicos quanto para Programas Profissionais, avaliam cinco quesitos: 1- sua proposta e objetivos, 2- seu corpo docente, 3- seu corpo discente e seus egressos, 4- sua produção intelectual e 5- sua inserção social, atribuindo pesos diferentes a cada quesito, e subdividindo cada quesito em diferentes itens, também com pesos diferenciados, para melhor se adequar a cada situação, área de conhecimento ou modalidade. O Relatório da Avaliação Quadrienal da Área de Ensino (ARAUJO-JORGE; BORBA; SOVIERZOSKI, 2017) aponta claramente a diferença da ficha de Rede:

a ficha de avaliação de Programas em Rede (associações de instituições de pelo menos de três estados diferentes) guardou relação com as fichas já utilizadas para as demais avaliações, mas com foco nos componentes mais relevantes: egressos (40\%) e inserção social (20\%) que, juntas, determinam o foco da avaliação. (ARAUJO-JORGE; BORBA; SOVIERZOSKI, 2017, p. 21). 
Tabela 1: Programas de Pós-Graduação em Rede avaliados pela CAPES em 2017

\begin{tabular}{|c|c|c|c|c|}
\hline $\begin{array}{l}\text { Programa de PG em } \\
\text { REDE (2017) }\end{array}$ & Instituição de Ensino & $\begin{array}{l}\text { Modalidade } \\
\text { Nível } \\
\text { (Ano de início; } \\
\text { total egressos) }\end{array}$ & $\begin{array}{c}\text { Área de } \\
\text { Avaliação } \\
\text { (\% resposta- } \\
\text { Ficha Rede)\# }\end{array}$ & $\begin{array}{c}\text { Ficha } \\
\text { utilizada e } \\
\text { Nota 2017 } \\
\text { (\% evasão/ } \\
\text { desligamento) }\end{array}$ \\
\hline $\begin{array}{c}\text { Biotecnologia - } \\
\text { Rede RENORBIO } \\
(22003010017 \text { P5) }\end{array}$ & $\begin{array}{l}\text { Universidade Federal } \\
\text { do Rio Grande do Norte } \\
\text { (UFRN) }\end{array}$ & $\begin{array}{l}\text { Acadêmico } \\
\text { Doutorado } \\
(2005)\end{array}$ & Biotecnologia & $\begin{array}{l}\text { Tradicional } \\
\text { Nota } 5\end{array}$ \\
\hline $\begin{array}{c}\text { Biodiversidade e } \\
\text { Biotecnologia - } \\
\text { Rede BIONORTE } \\
(12001015038 \mathrm{P} 1)\end{array}$ & $\begin{array}{l}\text { Universidade Estadual } \\
\text { do Maranhão (UEMA) }\end{array}$ & $\begin{array}{l}\text { Acadêmico } \\
\text { Doutorado } \\
\text { (2012) }\end{array}$ & Biotecnologia & $\begin{array}{l}\text { Tradicional } \\
\text { Nota } 4\end{array}$ \\
\hline $\begin{array}{c}\text { Biotecnologia e } \\
\text { Biodiversidade-Rede Pró- } \\
\text { Centro-Oeste } \\
(53001010100 \mathrm{P} 8)\end{array}$ & $\begin{array}{l}\text { Universidade de } \\
\text { Brasília (UNB) }\end{array}$ & $\begin{array}{l}\text { Acadêmico } \\
\text { Doutorado } \\
\text { (2013) }\end{array}$ & Biotecnologia & $\begin{array}{l}\text { Tradicional } \\
\text { Nota } 4\end{array}$ \\
\hline $\begin{array}{c}\text { Desenvolvimento e Meio } \\
\text { Ambiente-PRODEMA } \\
(22001018074 \mathrm{P} 6)\end{array}$ & $\begin{array}{c}\text { Universidade Federal } \\
\text { de Pernambuco } \\
\text { (UFPE) }\end{array}$ & $\begin{array}{l}\text { Acadêmico } \\
\text { Doutorado } \\
(2010)\end{array}$ & $\begin{array}{l}\text { Ciências } \\
\text { Ambientais }\end{array}$ & $\begin{array}{l}\text { Tradicional } \\
\text { Nota } 5\end{array}$ \\
\hline $\begin{array}{c}\text { Educação em Ciências e } \\
\text { Matemática - REAMEC- } \\
\text { UFMT - UFPA - UEA } \\
(50001019028 \mathrm{P} 3)\end{array}$ & $\begin{array}{l}\text { Universidade Federal } \\
\text { De Mato Grosso } \\
\text { (UFMT) }\end{array}$ & $\begin{array}{l}\text { Acadêmico } \\
\text { Doutorado } \\
(2010 ; 51)\end{array}$ & $\begin{array}{l}\text { Ensino } \\
(\mathbf{7 0 \%})\end{array}$ & $\begin{array}{c}\text { Rede } \\
\text { Nota } 5 \\
(\mathbf{1 \% )}\end{array}$ \\
\hline $\begin{array}{l}\text { Multicêntrico em Química } \\
\text { de MG (32005016039P0) }\end{array}$ & $\begin{array}{l}\text { Universidade Federal } \\
\text { de Juiz de Fora (UFJF) }\end{array}$ & $\begin{array}{c}\text { Acadêmico } \\
\text { Mest/Dout(2014) }\end{array}$ & $\begin{array}{l}\text { Química } \\
\text { (nd) }\end{array}$ & $\begin{array}{c}\text { Rede } \\
\text { Nota } 4 \\
\text { (nd) }\end{array}$ \\
\hline $\begin{array}{l}\text { Propriedade intelectual e } \\
\text { transferência de } \\
\text { tecnologia para inovação } \\
\text { PROFNIT - } \\
\text { (31102000001P6) }\end{array}$ & $\begin{array}{l}\text { Universidade Federal } \\
\text { De Alagoas (UFAL) }\end{array}$ & $\begin{array}{l}\text { Profissional } \\
\text { Mestrado } \\
\text { (2016) }\end{array}$ & $\begin{array}{l}\text { Administração } \\
\text { pública e de } \\
\text { empresas, } \\
\text { ciências } \\
\text { contábeis e } \\
\text { turismo (nd) }\end{array}$ & $\begin{array}{c}\text { Rede } \\
\text { Nota } 4 \\
(1 \%)\end{array}$ \\
\hline $\begin{array}{l}\text { Administração pública em } \\
\text { Rede Nacional } \\
\text { (53045009001P3) }\end{array}$ & $\begin{array}{l}\text { Ass. Nacional dos } \\
\text { Dirigentes das Inst. } \\
\text { Federais de Ens. } \\
\text { Superior (ANDIFES) }\end{array}$ & $\begin{array}{l}\text { Profissional } \\
\text { Mestrado } \\
\text { (2014) }\end{array}$ & $\begin{array}{l}\text { Admin.pública } \\
\text { e de empresas, } \\
\text { ciências } \\
\text { contábeis e } \\
\text { turismo (nd) }\end{array}$ & $\begin{array}{l}\text { Rede } \\
\text { Nota } 2 \\
\text { (nd) }\end{array}$ \\
\hline $\begin{array}{c}\text { Matemática em Rede } \\
\text { Nacional-PROFMAT } \\
(31075010001 \mathrm{P} 2)\end{array}$ & $\begin{array}{l}\text { Sociedade Brasileira De } \\
\text { Matemática (SBM) }\end{array}$ & $\begin{array}{c}\text { Profissional } \\
\text { Mestrado } \\
(2011 ; \mathbf{1 2 . 3 0 1}) \\
\end{array}$ & $\begin{array}{c}\text { Matemática / } \\
\text { probabilidade e } \\
\text { estatística(14\%) }\end{array}$ & $\begin{array}{c}\text { Rede } \\
\text { Nota } 5 \\
(23 \%) \\
\end{array}$ \\
\hline $\begin{array}{c}\text { Ensino de Física - } \\
\text { PROFIS } \\
(33283010001 P 5)\end{array}$ & $\begin{array}{l}\text { Sociedade Brasileira De } \\
\text { Física (SBF) }\end{array}$ & $\begin{array}{c}\text { Profissional } \\
\text { Mestrado } \\
(2013 ; \mathbf{1 . 2 3 2}) \\
\end{array}$ & $\begin{array}{c}\text { Astronomia / } \\
\text { Física } \\
(\mathbf{1 7 \% )}\end{array}$ & $\begin{array}{c}\text { Rede } \\
\text { Nota } 4 \\
(14 \%)\end{array}$ \\
\hline $\begin{array}{c}\text { Letras } \\
\text { PROF-LETRAS } \\
(23001011069 \mathrm{P} 5) \\
\end{array}$ & $\begin{array}{l}\text { Universidade Federal } \\
\text { do Rio Grande do Norte } \\
\text { (UFRN) }\end{array}$ & $\begin{array}{c}\text { Profissional } \\
\text { Mestrado } \\
(2013 ; \mathbf{2 . 1 8 5}) \\
\end{array}$ & $\begin{array}{c}\text { Linguística e } \\
\text { literatura } \\
(\mathbf{2 0 \%}) \\
\end{array}$ & $\begin{array}{c}\text { Rede } \\
\text { Nota } 4 \\
(4 \%) \\
\end{array}$ \\
\hline $\begin{array}{l}\text { Ensino de História- } \\
\text { PROFHISTORIA } \\
(31001017155 \mathrm{P} 1) \\
\end{array}$ & $\begin{array}{c}\text { Universidade Federal } \\
\text { Do Rio De Janeiro } \\
\text { (UFRJ) }\end{array}$ & $\begin{array}{c}\text { Profissional } \\
\text { Mestrado } \\
(2013 ; \mathbf{5 6 8}) \\
\end{array}$ & $\begin{array}{l}\text { História } \\
(24 \%)\end{array}$ & $\begin{array}{c}\text { Rede } \\
\text { Nota } 4 \\
(20 \%) \\
\end{array}$ \\
\hline $\begin{array}{c}\text { ProfArtes } \\
(41002016026 \mathrm{P} 1)\end{array}$ & $\begin{array}{c}\text { Universidade Do } \\
\text { Estado De Santa } \\
\text { Catarina (UDESC) }\end{array}$ & $\begin{array}{c}\text { Profissional } \\
\text { Mestrado } \\
(2014 ; \mathbf{3 0 9}) \\
\end{array}$ & $\begin{array}{l}\text { Artes } \\
(\mathbf{2 8 \%})\end{array}$ & $\begin{array}{c}\text { Rede } \\
\text { Nota } 4 \\
(2 \%)\end{array}$ \\
\hline
\end{tabular}

Fonte: Plataforma Sucupira, acesso em 11/8/2018 \#=\% de respostas de egressos ao questionário CAPES

https://sucupira.capes.gov.br/sucupira/public/consultas/avaliacao/consultaFichaAvaliacao.jsf;jse ssionid=2T8i1RxOtCVsGN14PDtyQeS8.sucupira-203 
Para alterar o foco da avaliação tradicional, centrada na produção acadêmica, para uma avaliação centrada $60 \%$ nos egressos e na inserção social, a ficha de Rede (Tabela 6 do relatório da Avaliação Quadrienal da Área de Ensino(p. 23) trazia como primeiro Quesito (20\% da avaliação) uma Avaliação da Rede, com novos elementos a serem considerados tais como: a Articulação entre as associadas (item 1.1, 20\%), o Credenciamento de associadas (item 1.2, 20\%), a Implantação e atualização (item 1.5, 20\%), além dos tradicionais Planejamento (item 1.2, 20\%) e Infraestrutura (item 1.3, 20\%). Como segundo Quesito (40\% da avaliação), estavam então os Discentes e egressos, com considerações sobre o processo de Seleção e avaliação (item 2.1, 15\%), Fluxo: número, conclusão e evasão (item 2.2, 25\%), e Qualidade e adequação (item 2.3, 60\%). Esses dois primeiros quesitos foram fortalecidos com um questionário implementado pela CAPES abordando diretamente os coordenadores das instituições associadas, para o Quesito 1, e os egressos, para o Quesito 2. Os outros $40 \%$ da avaliação foram divididos igualmente para os Quesitos 3 e 4. O Quesito 3, Corpo Docente (20\%) foi composto por 3 itens: adequação (item 3.1, 20\%), compatibilidade (item 3.2, 50\%) e produção intelectual (item 3.3, 30\%). O Quesito 4, Inserção Social (20\%), foi composto por 2 itens: Impacto na atuação profissional (item 4.1, 60\%, também aferido pelo questionário de egressos), e Visibilidade (item 4.2, 40\%). Podemos notar que o foco da avaliação realmente foi deslocado para o egresso, cuja "Qualidade e adequação" (item 2.3), avaliadas pelas respostas ao Questionário e pela produção intelectual registrada, bem como pelo "impacto na atuação profissional (item 4.1) passaram a ter o maior peso no conjunto da avaliação.

Essa ficha de avaliação de Redes não existia quando a REAMEC foi criada, nem quando registrou seus relatórios anuais 2012-2016. Isso já é diferente para a segunda grande rede operando hoje na Área de Ensino, o Prof-EPT (FREITAS e cols, 2017). Este Mestrado Profissional abriu 401 vagas em 2017, em seu primeiro edital nacional, envolvendo os seguintes institutos: IFSUL - Campus Charqueadas, IFRS - Campus Porto Alegre, IFFAR - Campus Jaguari, IFSC - Centro de Referência em Formação e EAD, IFPR - Campus Curitiba, IFSP - Campus Sertãozinho, IFFluminense - Centro de Referência, IFES - Campus Vitória, IFTM - Campus Uberaba Parque Tecnológico, IFSUDESTEMG - Campus Rio Pomba, IFGoiano - Campus Morrinhos, IFG - Campus Anápolis, IFBA - Campus Salvador, IFS - Campus Aracaju, IFPE - Campus Olinda, 
IFRN - Campus Mossoró, IFCE - Campus Fortaleza, IFAM - Campus Centro. Para 2018, o Prof-EPT ampliou suas Instituições Associadas e ofereceu um segundo edital com 820 vagas. Essa nova experiência de rede, desde seu nascedouro, já pode se organizar e refletir sobre o processo de avaliação à luz da nova ficha de rede, com a ênfase de $60 \%$ nos egressos e na inserção social. Mas é importante destacar que a Área de Ensino ofereceu 7.644 matrículas em mestrado isolados no quadriênio 2013-2016, o que correspondeu a $21 \%$ da demanda por essas vagas, pois os candidatos aos processos seletivos somaram 36.099 (ARAUJO-JORGE; BORBA; SOVIERZOSKI, 2017). Essa enorme demanda, por sua vez corresponde a menos de $10 \%$ dos números estimados para a meta 16 do Plano Nacional de Educação, que é formar em pós-graduação pelo menos $50 \%$ de professores da Educação Básica (cerca de 415 mil professores). Portanto, o aumento de oferta de vagas de mestrado e de doutorado em rede é claramente um desafio já apontado pelos números da avaliação de 2017.

\section{A EXPERIÊNCIA DE AVALIAÇÃO DA REAMEC EM 2017}

A Área de Ensino incentiva a integração e cooperação desde a sua criação, e os doutores egressos de programas mais antigos têm nucleado novos programas de mestrado e doutorado por todo o país. O relatório da avaliação quadrienal (ARAUJOJORGE; BORBA; SOVIERZOSKI, 2017) aponta cinco redes que se constituíram na Área: 1) REAMEC, a Rede Amazônica de Ensino de Ciências e Matemática; 2) as duas Associações estaduais: na Bahia, UFBA-UEFS e no Rio Grande do Sul, a UFRGSUFSM-FURG-UNIPAMPA; 3) o Prof-EPT; 4) o INCT-Ensino; e 5) o GT-Saúde. Os dois primeiros são relativos a programas acadêmicos, o terceiro a Mestrado Profissional, e os dois últimos são redes de pesquisa e cooperação.

A REAMEC, a Rede Amazônica de Ensino de Ciências e Matemática, primeiro se constituiu formalmente, em 2006, reunindo 25 instituições da Amazônia legal, para depois, em 2010, iniciar seu programa de Doutorado em rede intitulado "Educação em Ciências e Matemática" (Tabela 1), com o objetivo de formar pesquisadores na área de Ensino de Ciências e Matemática, fortalecendo a área na Região Amazônica, especialmente no âmbito das licenciaturas em Física, Química, Biologia, Matemática e Pedagogia. A escolha das três instituições associadas, que titulam os doutorandos, se 
deu pelos Programas Acadêmicos com maior densidade de orientadores e melhor produção: a Universidade Federal de Mato Grosso - UFMT (Cuiabá), que assumiu a sede principal da Rede, a Universidade do Estado do Amazonas - UEA (Manaus) e Universidade Federal do Pará - UFPA (Belém), que assumiram a função de polos regionais.

Cada polo acadêmico titula docentes das instituições da região, atendendo a três estados: a UFPA atende aos estados do AP, PA, MA, a UFMT atende a RO, MT e TO, e UEA atende a RR, AC e AM. As 26 instituições associadas à REAMEC, e que enviam seus docentes para os processos seletivos e incluem docentes doutores como orientadores, são: DezUniversidades Federais: Universidade Federal do Acre - UFAC, Universidade Federal do Amapá - UNIFAP, Universidade Federal do Amazonas UFAM, Universidade Federal do Maranhão - UFMA, Universidade Federal de Mato Grosso - UFMT, Universidade Federal do Oeste do Pará - UFOPA, Universidade Federal do Pará - UFPA, Universidade Federal de Roraima - UFRR, Universidade Federal do Tocantins - UFT; Sete universidades estaduais: Universidade do Estado do Amazonas - UEA, Universidade do Estado de Mato Grosso - UNEMAT, Universidade Estadual do Maranhão - UEMA, Universidade Estadual do Pará - UEPA, Universidade Estadual de Roraima - UERR, Universidade do Estado do Amapá - UEAP, Universidade Estadual da Região Tocantina do Maranhão - UEMASUL; Nove Institutos Federais de Educação, Ciência e Tecnologia: Instituto Federal de Educação, Ciência e Tecnologia do Acre - IFAC;Instituto Federal de Educação, Ciência e Tecnologia do Amapá - IFAP;Instituto Federal de Educação, Ciência e Tecnologia do Amazonas - IFAM, Instituto Federal de Educação, Ciência e Tecnologia do Maranhão IFMA, Instituto Federal de Educação, Ciências e Tecnologia de Mato Grosso - IFMT, Instituto Federal de Educação, Ciências e Tecnologia do Pará - IFPA,Instituto Federal de Educação, Ciências e Tecnologia de Rondônia - IFRO, Instituto Federal de Educação, Ciências e Tecnologia de Roraima - IFRR, Instituto Federal de Educação, Ciências e Tecnologia de Tocantins - IFTO; eduas universidades privadas:Centro Universitário Nilton Lins - UNINILTON /AM, Universidade do CEUMA (Maranhão) - UNICEUMA. 


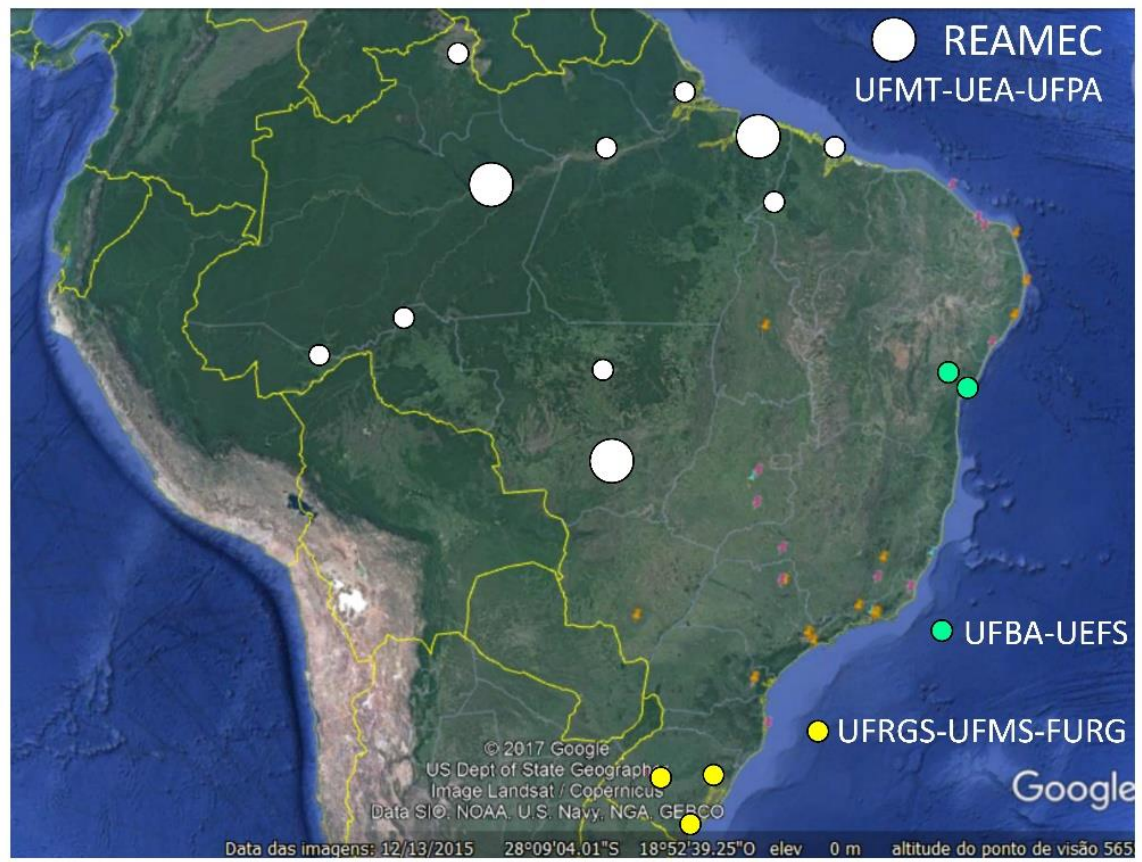

Figura 1: Mapa da REAMEC e outras associações acadêmicas na Área de Ensino (UFBAUEFS, e UFRGS-UFSM-FURG). Fonte: Relatório da Avaliação Quadrienal Ensino, 2017, pag. 19.

\section{O SUCESSO DA REAMEC INSPIRA NOVAS REDES NA ÁREA DE ENSINO}

Passando por sua primeira avaliação quadrienal, a REAMEC mostrou um sucesso extraordinário, e alcançou a nota 5 , tendo indicadores que a poderiam levar para nota 6 , o que não ocorreu devido à decisão da Área de não promover ou rebaixar nenhum programa mais de um ponto.

A primeira turma foi iniciada em 2011 e os processos seletivos são bienais (Tabela 2). A meta inicial de formar 100 doutores deve ser superada, pois a oferta de vagas já chegou a 164 e o edital de 2018/2019 já ofereceu mais 60 vagas, mais do que duplicando a meta inicial. De 2014 a 2017 já se titularam 72 doutores, com a expectativa de alcançar pelo menos 224 doutores na Amazônia com o edital de 2018/2019, para um programa que opera com 35 docentes permanentes e diversos colaboradores. Quase quatro centenas de candidatos se apresentaram nos processos seletivos (informações coletadas pela Área em 2013 e 2015, uma vez que essa informação não é registrada na plataforma Sucupira), tendo sido ampliadas as vagas de 
30, para 40 e para 60, para maior absorção da demanda. A taxa de evasão de $1 \%$ foi insignificante no quadriênio e o tempo de titulação foi de 47,6 meses.

Tabela 2: Indicadores de Progresso da REAMEC 2011-2018

\begin{tabular}{|l|c|c|c|c|c|}
\hline Indicadores I Anos & $\mathbf{2 0 1 1 - 2 0 1 2}$ & $\mathbf{2 0 1 3 - 2 0 1 4}$ & $\mathbf{2 0 1 5 - 2 0 1 6}$ & $\mathbf{2 0 1 7}$ & Total \\
\hline Docentes Permanentes & 30 & 37 & $52-55$ & 31 & 55 \\
\hline Docentes Colaboradores & 27 & 28 & $33-35$ & 19 & 35 \\
\hline Candidatos & 86 & 108 & 104 & 92 & 390 \\
\hline Vagas & 30 & 44 & 60 & 30 & 164 \\
\hline Matrículas ativas & 30 & 74 & 104 & 111 & \\
\hline Doutores Egressos & -- & 10 & 41 & 21 & 72 \\
\hline Evasões* & 0 & 1 & 0 & 1 & 2 \\
\hline Artigos em periódicos & -- & $60-100$ & $204-139$ & 205 & 708 \\
\hline Artigos A1-A2-B1 & -- & $32-41$ & $89-65$ & nd & 227 \\
\hline $\begin{array}{l}\text { Capítulos de livros + } \\
\text { livros organizados }\end{array}$ & -- & $40-53$ & $110-125$ & 124 & 452 \\
\hline $\begin{array}{l}\text { Trabalhos completos em } \\
\text { Anais de Eventos }\end{array}$ & -- & $151-119$ & $237-214$ & nd & 721 \\
\hline
\end{tabular}

Fonte: Plataforma Sucupira; *Doença grave; nd= não determinado na plataforma Sucupira

Mesmo com o aumento de docentes que a REAMEC implementou no biênio 2015-2016, é impressionante que a demanda de mestres com vínculo empregatício nas Universidades da rede, interessados em se doutorar, seja quase 2,5 vezes maior do que a oferta de vagas (Tabela 2). Esses números confirmam não apenas a justeza da iniciativa de criação e implementação da REAMEC, como a necessidade de se manter ativa a rede ainda por alguns anos, para atender essa grande demanda na região amazônica e contribuir com as metas do PNPG quanto a número de doutores no país e redução de assimetrias regionais.

Esses resultados também indicam que o grande número de mestres que estão sendo formados nas Áreas de Ensino e Educação, inclusive com os Mestrados Profissionais em rede, deverá aumentar ainda mais a demanda de doutorados em todo o país. Isso exigirá que os atuais doutorados em Ensino ampliem suas vagas e que outros programas de Doutorados em Rede, a exemplo da REAMEC, sejam constituídos nos próximos anos, especialmente com caráter descentralizado nas regiões não atendidas pelos atuais Doutorados em Ensino ou Educação. 


\section{MECANISMOS DE GESTÃO DA REAMEC E AUTOAVALIAÇÃO}

A gestão da REAMEC é feita por uma coordenação geral na sede (UFMT), coordenações locais nos polos acadêmicos (UEA, UFPA, UFMT) e um Colegiado do Programa, com 09 representantes estaduais: UFRR (Roraima), UNIR (Rondônia), UEA (Amazonas), UFT (Tocantins), UFAC (Acre), UFMT (Mato Grosso), UNIFAP (Amapá), UFPA (Pará), UEMA (Maranhão). Essa estrutura tem funcionado a contento segundo os relatos na Plataforma Sucupira. Esse mecanismo tem inspirado osdemais programas, e, particularmente na Área de Ensino, o Prof-EPT, que também estruturou uma coordenação geral (nacional) e coordenações locais em cada instituição associada, para dar mais organicidade ao conjunto da rede (FREITAS e cols., 2017). Na rede reconhecem-se os 26 representantes institucionais das IES associadas.

Para auto avaliação, a REAMEC montou uma série de comissões com o objetivo de discutir os mais diversos aspectos do programa e que têm íntima ligação com a coordenadoria do programa, que se reúne periodicamente e se mantém ativa e atuante, apesar das dificuldades logísticas e financeiras. Os relatórios anuais da plataforma Sucupira, acessíveisa qualquer cidadão de modo transparente no portal da CAPES, também trazem informações muito interessantes sobre a autoavaliação, que sintetizamos no Quadro1. São os pontos fortes (1 a 9) e fracos da Rede (10 a 14), segundo sua própria autoavaliação nos relatórios anuais (2013 a 2017). O maior problema tem sido o fomento à rede, que está em desacordo com a política traçada no PNPG para as Redes de Pós-Graduação, que diz explicitamente:

Como no último Plano, no próximo decênio o SNPG deve usar os indicadores de solidariedade como instrumento para a ampliação do parque nacional de pós-graduação, visando à interiorização do sistema e à equalização das oportunidades. O desafio será aliar a necessidade de contemplar o espalhamento não-linear das áreas do conhecimento, ou seja, estabelecer prioridades para o direcionamento futuro do crescimento do SNPG, combatendo as assimetrias das áreas de conhecimento, à exigência de criação de centros de excelência em ensino e pesquisa de padrão internacional. (BRASIL, 2010, p.293). 
Quadro 1: REAMEC: Pontos fortes a destacar -1 a 9- e a melhorar -10 a 14 -

1. Integração dos doutores da Amazônia Legal da área de Educação em Ciências e Matemática, em prol da formação de futuros doutores para IES associadas, concorrendo para sua fixação de novos doutores na região;

2. Integração de doutores e doutorandos em pesquisas de interesse para a região Norte do Brasil, na área de Educação em Ciências e Matemática;

3. Ter como uma de suas metas o intercâmbio entre as Instituições de Ensino Superior, contribuindo para a formação de docentes que atuam em cursos de Licenciaturas nessas áreas;

4. Criação de Núcleos de Estudos e Pesquisas nos Estados, concorrendo para nucleação de futuros programas de Pós-Graduação nos diferentes estados.

5. Alto nível de comprometimento de docentes doutores e doutorandos com o Programa. 6. A manutenção da regularidade das Reuniões do Colegiado (formados pelos 09 representantes Estaduais). São três reuniões ordinárias/ano, que envolvem deslocamentos e no mínimo 03 dias de trabalho, com pauta imensa e densa.

7. Convênio de Cooperação Técnico científica entre as IES, assinado por todos os reitores das 25 IES associadas.

8. A repercussão nacional positiva da proposta do Programa em Rede, que fez aumentar o interesse de novos docentes colaboradores. O Programa conta atualmente com um banco de colaboradores de 15 doutores de IES pertencentes a outras Regiões do país (USP, UFMS, UNICAMP, UFSCAR, UFRGS, FURG, UFMG, UNIFESP).

9. É altamente positiva a integralização dos discentes do curso, com prazo de 4 anos; nas três turmas que até agora ingressaram, somando 134 doutorandos, só houve 02 evasões até 2016.

10. PROAP muito abaixo da realidade de Programa em Rede de IES associadas. Impossível manter três polos acadêmicos (UFMT, UFPA e UEA) e mais de 100 discentes com os recursos recebidos. A mobilidade entre os polos e Estados e a manutenção da gestão do programa ficam fragilizadas por falta de recursos financeiros.

11. Falta de bolsa de estudos ou outras formas de auxílio financeiro, sobrecarregandofinanceiramente os doutorandos, especialmente considerando a necessidade de deslocamentos de sua IES de origem aos Polos Acadêmicos para atividades de estudos, orientação e formação.

12. Necessidade de negociações permanentes com as Fundações de Apoio a Pesquisa (FAP) e a CAPES para a ampliação do número de bolsas. Além disso, nem todos os estados dispõem de FAP. Em 2012, em negociação com as Fundações de Apoio, 06 doutorandos receberam bolsa auxílio (FAPEAM), 3 auxílios deslocamento da FAPEMAT e um do Projeto Observatório da UFPA. EM 2013, foram 16 bolsas mantidas pela FAPEAM, 06 bolsas FAPESPA e a FAPEMAT, 13 bolsas, sendo que esta última disponibiliza bolsas somente em períodos de oferta de disciplinas e orientação, ou seja, configuram-se, como auxílios deslocamento. Os outros 12 doutorandos são subsidiados por suas IES em períodos de deslocamentos.

13. A produção bibliográfica docente e discente em estratos superiores do Qualis Periódicos-Ensino.

14. A inserção internacional em eventos e periódicos, e formalização de acordos e convênios internacionais para intercâmbio com IES estrangeiras, especialmente na Venezuela, México e Espanha, em andamento.

Fonte: relatórios anuais na Plataforma Sucupira 
ISSN: $2594-4827$

\section{EGRESSOS: COMO AVALIARAM A REAMEC EM 2017}

Dos 51 egressos, 36 responderam ao questionário enviado pela DAV (70\%) e fizeram avaliação excelente ou muito boa em todos os itens avaliados (Tabela 3). Essa adesão ao processo de avaliação foi extraordinária, considerando que os demais programas em rede ficaram em torno de 14 a $28 \%$ de respostas dos egressos ao questionário da CAPES (Tabela 1). O vínculo do programa com seus egressos é um componente essencial a ser trabalhado. Possivelmente, os 48 meses de vivência no Doutorado fortalece mais esses vínculos do que os 24 meses do Mestrado, a julgar pela grande diferença obtida nos questionários entre os egressos da REAMEC comparativamente aos dos demais Programas em Rede (Tabela 1).

Tabela 3: Resultados da pesquisa com egressos feita pela CAPES para a avaliação quadrienal 2013-2016

\begin{tabular}{|l|c|c|c|c|c|}
\hline \multicolumn{1}{|c|}{ Pergunta respondida pelos egressos } & Excelente & $\begin{array}{l}\text { Muito } \\
\text { Boa }\end{array}$ & Adequado & Regular & Insuficiente \\
\hline $\begin{array}{l}\text { 1. Avalie a infraestrutura dedicada à } \\
\text { gestão do curso - secretaria, } \\
\text { coordenação, etc. * }\end{array}$ & 13 & 12 & 8 & 2 & 1 \\
\hline $\begin{array}{l}\text { 2. Avalie a infraestrutura para ensino } \\
\text { usadas no curso - salas de aula, } \\
\text { biblioteca, serviços de } \\
\text { videoconferência, laboratórios, etc. }\end{array}$ & 16 & 12 & 7 & 1 & 0 \\
\hline $\begin{array}{l}\text { 3. Avalie o corpo docente do curso * } \\
\text { 4. Frequência de contato presencial ou } \\
\text { por meio eletrônico com docentes e } \\
\text { discentes de outras instituições da } \\
\text { rede ao longo do curso \# }\end{array}$ & 22 & 12 & 2 & 0 & 0 \\
\hline $\begin{array}{l}\text { 5. Avalie quanto sua postura como } \\
\text { professor/profissional mudou em } \\
\text { razão da conclusão do curso ** }\end{array}$ & 34 & 2 & 0 & 0 & 0 \\
\hline $\begin{array}{l}\text { 6. Avalie a importância do curso para } \\
\text { o seu avanço na carreira de } \\
\text { professor/profissional. \#\# }\end{array}$ & 34 & 0 & 0 & 0 & 0 \\
\hline 7. Recomendaria o curso? & 33 & 1 & & 0 & 0 \\
\hline
\end{tabular}

Fonte: Coordenação da Área de Ensino, 2017, Avaliação Quadrienal, não publicado.

* Regular= com algumas inadequações; Insuficiente=inadequada;

\# Excelente=Muito frequentemente; Muito boa=frequentemente; Adequado=Regular ** Excelente=Estou muito melhor; Muito boa=Estou melhor; \#\# Muito importante $* * *$ Excelente $=$ Certamente sim; Muito boa $=$ Sim 
Além disso, toda a vasta produção intelectual do programa (Tabela 2) está intimamente ligada com as teses defendidas, que podem ser acessadas em sua totalidade na página institucional do programa. Isso ocorre porque o regulamento da REAMEC exige dos estudantes a publicação de artigo como um dos requisitos para realização da defesa da tese, de modo a fortalecer o programa em relação à produção científica.

\section{TESES DA REAMEC: O QUE DIZEM SEUS TÍTULOS E RESUMOS?}

A Figura 2A e B mostram duas nuvens de palavras construídaspelo programa Wordle.net com os títulos das primeiras 72 teses defendidas na REAMEC, de 2013 a 2017, capturados em planilhas a partir da plataforma Sucupira. As palavras que mais se destacam são as que aparecem com maior frequência nos títulos das teses, e indicam os temas centrais abordados no Programa: Formação, Professores, Ensino, Ciências e Matemática são as mais frequentes (Figura 2A). Esses temas centrais refletem a estrutura da proposta da REAMEC, que tem uma área de concentração com a mesma denominaçãodo curso (Educação em Ciências e Matemática) e duas linhas de pesquisa, uma em Formação de Professores para aEducação em Ciências e Matemática e outra em Fundamentos e Metodologias para a Educação em Ciências e Matemática, ambas abrangentes.Removendo-se as palavras mais frequentes da Figura 2A, emergem os temas que orbitam no plano seguinte do interesse dos doutorandos, na Figura 2B: Educação, Aprendizagem.

Das 72 teses já concluídas, 40 foram desenvolvidas na linha de Formação de Professores e 32 na linha de Fundamentos e Metodologias. Outra distribuição possível de ser feita com o estudo dos títulos das teses é quanto aos temas: 35 teses sobre a Educação em Ciências, 30 sobre Educação Matemática, três sobre formação em pedagogia, uma sobre educação em saúde, uma sobre educação profissional e tecnológica e uma sobre extensão. Um estudo mais detalhado sobre o conteúdo das teses desenvolvidas está em preparação e foge ao escopo deste artigo, mas com certeza esse tema é e será prioritário na avaliação da pós-graduação: qual é a contribuição que o conhecimento produzido na pós-graduação tem agregado ao patrimônio da sociedade? Como parar de contar artigos e perceber o que comunicam de mais relevante essas teses e produções acadêmicas correlatas? Pela análise da nuvem de palavras com os títulos 
dessas produções, podemos verificar a identidade temática dos trabalhos com o programa, e também inferir sobre uma rica diversidade de assuntos abordados e também de níveis de ensino estudados: dos anos iniciais, ao ensino médio e ao ensino superior, com muita ênfase na formação de professores nas licenciaturas de ciências, matemática e pedagogia.

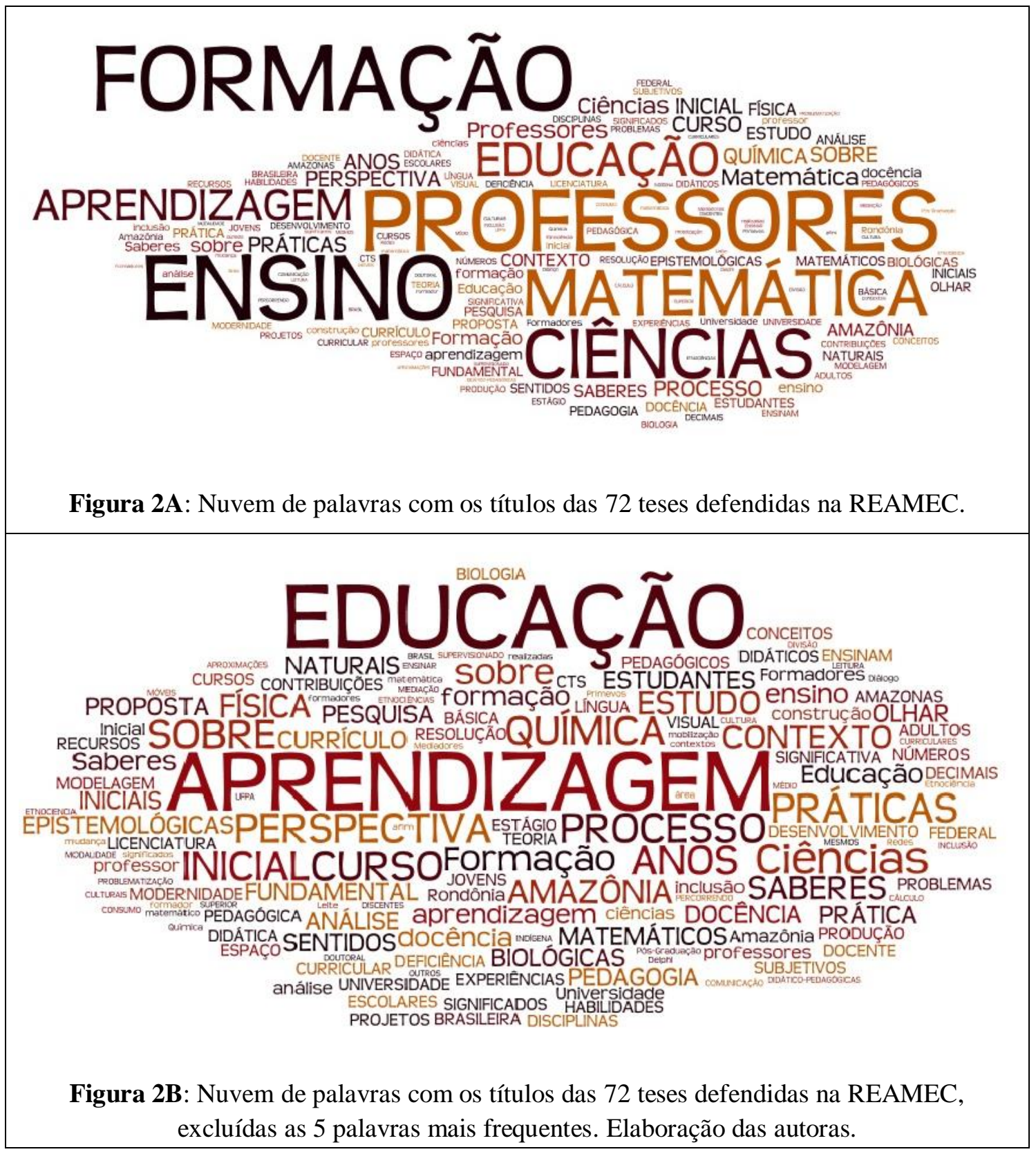

As 72 teses registraram 299 palavras chaves, número que se reduz a 215 quando agregados pela frequência. A análise de conteúdo dessas 215 palavras-chaves evidencia as categorias expostas na Tabela 4. Os "temas estudados" (macrocategoria 1) são muito 
variáveis, abrangendo 46 subcategorias, aplicadas a 10 "tipos ou níveis de ensino" (macrocategoria 2), e a 10 "campos disciplinares" diferentes (macrocategoria 3). As palavras-chave propostas pelos autores também chamam atenção para "metodologias utilizadas" nos estudos (macrocategoria 4), "recursos educacionais" desenvolvidos, aplicados ou testados (macrocategoria 5) e até mesmo autores referenciados (macrocategoria 6). Nos surpreendeu o fato dos títulos, e das palavras chave não chamarem a atenção para o importante recorte territorial das pesquisas, uma vez que "territorialização" (macrocategoria 7) que indica estudos feitos na Amazônia, ou nas particularidades de seus estados, comunidades ou populações ribeirinhas ou quilombolas, só aparecerem 5 vezes no total de 299 palavras (1,6\%). Essa é uma observação que deve ser feita sobre os estudos regionais que, para serem valorizados na dimensão em que agregam justamente o valor sobre o novo não estudado, precisa ser destacado no título ou na palavra-chave do trabalho de conclusão do processo formativo, seja ele uma monografia, uma dissertação, uma tese ou um artigo em periódico.

\section{A INSERÇÃO SOCIAL DAS REDES: COMO ANALISAR?}

No Documento de Área de Ensino, a inserção social é conceituada especialmente em termos de "impacto educacional e social. Aqui deve ser incluído o impacto dos egressos, mantidos nesse status de "egresso" por 5 anos após a titulação no Programa”. Afirma também que épreciso

diferenciar bem que a inserção social não se refere à produção, mas a ações na sociedade, tais como: cursos e projetos de extensão, cursos de aperfeiçoamento, especialização e atualização; feiras de ciência, gincanas, atividades não formais; construção / execução de políticas públicas; redução do gasto público e benefício direto a população ou organização de sociedade". (ARAUJO-JORGE, BORBA, SOVIERZOSKI; 2016, pag. 28)

Portanto, nas fichas tradicionais, a inserção social dos programas foi avaliada indiretamente, pelo (i) o impacto educacional e social (produção de material didático, parcerias com as redes de ensino/saúde, formação de profissionais para os sistemas de ensino/saúde, assessorias, projetos de extensão, divulgação científica etc.); e (ii) o impacto científico e tecnológico (participação em atividades científicas, organização de 
ISSN: $2594-4827$

eventos, criação de produtos e processos tecnológicos, com especial relevância as atividades de extensão realizadas pelos docentes e discentes.

Com a ficha de rede e os questionários aplicados pela CAPES, foi possível perguntar diretamente aos doutores egressos como eles avaliavam a importância do curso para o seu avanço na carreira de professor/profissional (Tabela 3, pergunta 6) e se sua postura como professor/profissional mudou em razão da conclusão do curso (pergunta 5).

Tabela 4: Categorias agregadas por temas ao se analisar as 299 palavras-chave das teses produzidas na REAMEC

\begin{tabular}{|c|c|}
\hline $\begin{array}{l}\text { Macro categoria } \\
\quad(=\text { número } \\
\text { identificado }) \\
\end{array}$ & $\begin{array}{l}\text { Termos das subcategorias } \\
\text { (nos parênteses o quantitativo quando maior que } 1 \text { ou } 2 \text { inserções) }\end{array}$ \\
\hline $\begin{array}{l}\text { (i) Temas } \\
\text { estudados } \\
=46\end{array}$ & $\begin{array}{l}\text { Professores/ Docência/Formação de professores (37); Saberes (14); } \\
\text { Inclusão/educação inclusiva (10); Educação Científica (7); Contextualização/ } \\
\text { Cultura/CTS (7); Aprendizagem (6); História (6); } \\
\text { Praxeologia/Práticas (6); Ensino-aprendizagem (3); Disciplinas (3); } \\
\text { Estágios (3); Etnociência (3); Projeto Pedagógico de Curso (3); } \\
\text { Sentidos Subjetivos (3); com } 2 \text { palavras: Ciclo de Políticas; Concepções de } \\
\text { professores; Epistemologia; Estado da arte; Habilidades e competências; } \\
\text { Identidade docente; Interculturalidade; Interdisciplinaridade; Percepções; com } \\
1 \text { palavra: Alfabetização científica; Avaliação formativa; Comunicação; } \\
\text { Construção de conhecimentos; Constructos multidimensionais da resiliência } \\
\text { acadêmica; Espaços socioambientais; Ética; Experiência; Leitura; } \\
\text { Necessidades psicossociais; Panorama; Performatividade; Políticas } \\
\text { curriculares; Populações tradicionais; Pós-modernidade; Pressupostos } \\
\text { teóricos; Prevenção; Qualidade de ensino; Sala de aula; Teses de Doutorado; } \\
\text { Tipos de Provas; Transposição Didática; Validações Empíricas e Teóricas }\end{array}$ \\
\hline $\begin{array}{l}\text { (ii) Tipo/ Nível } \\
\text { de Ensino } \\
=10\end{array}$ & $\begin{array}{l}\text { Ensino superior (4); Educação Básica (3); com } 2 \text { palavras: Educação de } \\
\text { Jovens e Adultos (EJA), Educação Indígena, Educação Profissional e } \\
\text { Tecnológica (EPT); Anos iniciais; Educação a distância; com } 1 \text { palavra: } \\
\text { Educação do Campo; Extensão universitária; Espaços Formais e não Formais }\end{array}$ \\
\hline $\begin{array}{l}\text { (iii) Disciplinas } \\
\text { abordada } \\
=10\end{array}$ & $\begin{array}{l}\text { Educação Matemática (18); Ciências (6); Ciências Biológicas (7); Educação } \\
\text { Ambiental (5); Química (3); Física (3); Neurociência (2); Pedagogia (2); } \\
\text { Saúde (1); Língua Portuguesa (1). }\end{array}$ \\
\hline $\begin{array}{l}\text { (iv) } \\
\text { Metodologias } \\
=24\end{array}$ & $\begin{array}{l}\text { Pesquisa narrativa (4); Pesquisa-ação (3); Discurso (3); Autobiografia (2); } \\
\text { Método Quali-Quantitativo/Misto (2); Teoria Fundamentada (2); com } 1 \\
\text { palavra: Análise Textual Discursiva; } \\
\text { Aula de campo; Categorias; Diálogo; Dispersão Controlada; Etnografia } \\
\text { Grupo colaborativo; Hermenêutica Crítica; História de vida; Instrumentação } \\
\text { Eletrônica; Interação de grupos; Método de Pesquisa em Educação; } \\
\text { Metodologia de Ensino; Metodologia de Projetos; Pedagogia do sentido; } \\
\text { Recontextualização por hibridismo; Semiótica sincrética; Teoria da formação } \\
\text { por etapas das ações mentais }\end{array}$ \\
\hline
\end{tabular}




\begin{tabular}{|l|l|}
\hline $\begin{array}{l}\text { (v) Recursos } \\
\text { educacionais } \\
=16\end{array}$ & $\begin{array}{l}\text { Currículo (3); Resolução de problemas (3); Conhecimentos para a Docência } \\
\text { (2); Livro didático (2); Recursos Didáticos (2); com 1 palavra: Calculadora } \\
\text { Musical; Dispositivos Móveis; Jogos de linguagem; Jornada do Herói; } \\
\text { Laboratórios Vivos; Metáforas Criativas; } \\
\text { Registros de Representações; Regras; Sequência didática; Tabuleiro de } \\
\text { Decimais; Tecnologias digitais }\end{array}$ \\
\hline $\begin{array}{l}\text { (vi) Autores = 4 } \\
\text { (vii) Territoria- } \\
\text { lização=5 }\end{array}$ & $\begin{array}{l}\text { Amazônia; Paiter; Pedagogia Freireana; Terapia Wittgensteiniana } \\
\text { Setentrional; Quilombolas }\end{array}$ \\
\hline (viii) Outros = 4 & $\begin{array}{l}\text { Iniciação à Docência (PIBID) (3); Formas de vida; Institutos Federais; } \\
\text { Pedagogia acordo Brasil/Japão }\end{array}$ \\
\hline
\end{tabular}

Fonte: Elaboração das autoras. Dados acessados na Plataforma Sucupira, 11/8/2018.

Desse modo a inserção social da rede foi avaliada e considerada excelente, e o programa permitiu com que eles mudassem a sua postura. Os respondentes foram unânimes em considerar que o curso foi importante para o seu avanço na carreira de professor. E ao final do questionário, na pergunta aberta, alguns trechos foram inseridos no parecer da avaliação: EGRESSO 1: "O objetivo do curso em formar doutores na Amazônia brasileira é de extrema importância. Posto que a cultura e a produção de conhecimento no Brasil incidem na região sul e sudeste. Considerando que a principal motivação deste fato sempre foi a falta de doutores na Região Norte e a ausência de FAP no norte brasileiro, sem dúvida nesse aspecto, o curso é Muito Relevante para o desenvolvimento socioeconômico da região amazônica e para a Pós- Graduação do homem amazônico.”; EGRESSO 2: "Tive uma excelente formação!"; EGRESSO 3: "O doutorado em Rede foi para mim uma excelente oportunidade para me qualificar e com isso melhorar significativamente minha prática docente no ensino superior e a inserção na pesquisa, se não fosse esse programa não teria condições de fazer um doutorado, pois como resido em Roraima, aqui são raras as oportunidades de oferta de cursos de pós graduação de mestrado e doutorado, sou muito grata e defendo que é necessário a ampliação dos programas de mestrado e doutorado em rede, principalmente na região norte que é tão carente e esquecida de investimentos em pós graduação.”; EGRESSO 4: "Sou melhor professora, após a conclusão desta Pós-Graduação, em termos de produção de sínteses e de textos acadêmicos, em relação às minhas bases epistemológicas e ao conhecimento da região amazônica. A experiência de conviver pessoalmente com as cidades, com as pessoas e com a comunidade acadêmica, de instituições tanto de Mato Grosso e do Pará quanto do polo do Amazonas, melhorou minhas análises das 
condições da formação de professores e da sustentação da vida material e cultural, na Amazônia Legal."; EGRESSO 5: "Foi um divisor de águas na minha vida profissional. Tive acesso a discussão e formação epistemológica que até então nem fazia ideia que existiam." EGRESSO 6: "Sou do Sul do Maranhão, região longínqua dos grandes centros urbanos e desenvolvimento acanhado. Sem o REAMEC, meu ideal de fazer doutorado não se teria tornado realidade, para mim e para os que de mim dependem, como professora formadora de professores para a educação básica. Poucos sabem do que estou falando, se soubessem jamais cogitariam pensar extinguir esse programa."

\section{CONSIDERAÇÕES FINAIS}

Os resultados da avaliação quadrienal da CAPES de 2017 evidenciaram que a Área de Ensino foi a que mais cresceu no Brasil no quadriênio 2013-2017, aumentando em $44,5 \%$ o número de matrículas ofertadas no SNPG, como bem retratou matéria na mídia $^{3}$. Com a entrada em funcionamento do Prof-EPT, a expectativa de continuidade de apresentação de novos programas isolados e a organização de novas redes, o próximo quadriênio deverá manter essa tendência de crescimento, sustentando as diretrizes do PNPG, apesar da crise financeira do sistema. No caso do Doutorado em Rede na Amazônia, a REAMEC vem mantendo perto de uma centena de candidatos a cada edital, mesmo com oferta diferente de vagas, mesmo com pouquíssima disponibilidade de bolsas (dos 72 egressos, apenas 6 obtiveram bolsas das FAP estaduais), e com a necessidade de cursar o doutorado mantendo ativa sua carga horária docente, o que sobrecarrega o professor universitário que ao mesmo tempo é docente e doutorando. $\mathrm{O}$ mesmo acontecerá com os mestrandos profissionais que cursarão o Prof-EPT, mas a previsão é que essa dificuldade opere como um estímulo à superação e não como um obstáculo intransponível. Esses têm sido os resultados obtidos com a conclusão dos doutorados pelos estudantes da REAMEC, segundo a avaliação realizada.

Acreditamos que esses processos em rede não apenas podem potencializar a escala de formação de mestres e doutores, como a experiência de cooperação e solidariedade entre docentes de diferentes instituições, em prol de um objetivo comum,

\footnotetext{
${ }^{3}$ http://www1.folha.uol.com.br/educacao/2018/01/1953342-area-que-capacita-docentes-e-a-que-maiscresce-no-mestrado-no-pais.shtml
} 
um projeto maior, uma missão regional. Implantar e consolidar a REAMEC tem sido um projeto de vida para muitos docentes do programa. Algumas respostas de coordenadores das instituições locais no questionário da CAPES são reveladoras desse engajamento e foram destacadas para partilhar a voz desses importantes atores no processo de formação de doutores na Amazônia: COORDENADOR 1: "O doutorado em Educação em Ciências e Matemática da Rede Amazônica de Educação em Ciências Matemática, tem contribuído para diminuir o déficit de doutores na área de Educação em Ciências e Matemática. Todos os doutorandos são de IES associadas a REAMEC e atuam em Licenciaturas da área. Assim, o Programa está diretamente comprometido com a formação de formadores de professores que atuam ou atuarão na Educação Básica.”; COORDENADOR 2: "O programa é de suma relevância para a formação de doutores na Amazônia, considerando que isto amplia e potencializa a educação na região amazônica."; COORDENADOR 3: "Importante a consolidação do programa de doutorado e a perspectiva de criação de mestrado em rede, nos moldes da REAMEC, para a região e país."

Após essa experiência de avaliação, consideramos ainda válidas e atuais as orientações do V PNPG que destacamos a seguir:

Estímulo à formação centros de excelência e de redes de pesquisa e pós-graduação, para a formação regional de recursos humanos e aumento da massacrítica de pesquisa, com ênfase no desenvolvimento regional e superação dasdesigualdades socioeconômicas;

Para alcançar essas metas, as seguintes diretrizes deverão ser observadas, implementadas por ações específicas e induzidas e definidas pelos governos e acomunidade:

- estímulo à formação de redes de pesquisa e pós-graduação, envolvendo parceriasnacionais e internacionais, no nível da fronteira do conhecimento, com vistas àdescoberta do "novo" e do inédito;

- ênfase nas questões ambientais, associadas à busca do desenvolvimentosustentável e ao uso de tecnologias limpas;

- garantia do apoio ao crescimento inercial do SNPG, favorecendo não obstanteo uso de parcelas significativas do orçamento das agências como instrumentode implantação de políticas inovadoras; (BRASIL, 2010, p. 294) 


\section{AGRADECIMENTOS}

As autoras agradecem a Profa. Marta Maria Pontin Darsie, da UFMT, por informações e reflexões sobre a REAMEC, ao Prof. Rony Freitas, por informações e reflexões sobre o Prof-EPT, e ao Prof. Paulo Roberto Vasconcellos-Silva, por introdução na metodologia de uso das nuvens de palavras. Essa pesquisa tem o apoio da Fundação Oswaldo Cruz, Instituto Oswaldo Cruz, através do projeto "Estudos de Egressos em Ensino" previsto no INCT-Ensino e Comunicação, projeto integrante da PG-Ensino em Biociências e Saúde. 


\section{BIBLIOGRAFIA}

ARAÚJO-JORGE, T.C.; BORBA, M. C.; SOVIERZOSKI, H.H. Documento de Área - Ensino 2016. Disponível em:

<http://capes.gov.br/images/documentos/Documentos_de_area_2017/DOCUMENTO_AREA_ ENSINO_24_MAIO.pdf>

ARAÚJO-JORGE, T.C.; BORBA, M. C.; SOVIERZOSKI, H.H. Relatório de Avaliação - Área de Ensino 2013-2016, 2017. Disponível em:

$<$ http://capes.gov.br/images/stories/download/avaliacao/relatorios-finais-quadrienal-

2017/20122017-ENSINO-quadrienal.pdf>

ARAÚJO-JORGE, T. C.; BARBOSA H.S.; OLIVEIRA, R. L. Uma escola para a ciência e a saúde: 111 anos de ensino noInstituto Oswaldo Cruz. 1. ed. Rio de Janeiro: Instituto Oswaldo Cruz, 2012. v. 1. 331p. Disponível em:

<http://www.fiocruz.br/ioc/media/Livro_111\%20anos\%20do\%20Ensino\%20no\%20IOC.pdf>

BRASIL, PLANO NACIONAL DE PÓS-GRADUAÇÃO (PNPG) 2005-2010, 2004. Disponível

em:

<http://www.capes.gov.br/images/stories/download/editais/PNPG_2005_2010.pdf>

BRASIL, PLANO NACIONAL DE PÓS-GRADUAÇÃO (PNPG) 2011-2020, Volume 1. 2010. Disponível em: <http://www.capes.gov.br/images/stories/download/Livros-PNPG-Volume-IMont.pdf>

FREITAS, R.C.O.; BARREIRO, C.B.; FRANCO F.S.C.; MURTA, R.; SOUZA, R.R. O Mestrado Profissional em Educação Profissional e Tecnológica em Rede Nacional: considerações preliminares. Educ. Prof. Tecnol.Rev. v. 1, n. 1, p. 74-89, 2017. Disponível em:

MEDEIROS, M.L.S.; RONDON, J.N.Rede Nordeste de Biotecnologia (RENORBIO): um panorama atual doPrograma. Interações, Campo Grande, MS, v. 19, n. 1, p. 103-117, 2018, DOI: http://dx.doi.org/10.20435/inter.v19i1.1124

RIBEIRO, D. Os cursos de pós-graduação. Encontros com a Civilização Brasileira, Rio de Janeiro: Civilização Brasileira, 1980.

SANTOS, C.M. Tradições e contradições da pós-graduação no Brasil. Educ. Soc., Campinas, vol. 24, n. 83, p. 627-641, agosto 2003, disponível em http://www.cedes.unicamp.br 